and fascia the thin fibres of the latissimus dorsi are first recognised, and then the strong fascia at the outer border of the rectus. This is incised and the upper border of the quadratus lumborum is next seen running downwards and outwards. The finger is inserted above it and feels for the posterior surface of the kidney through the fat and cellular tissue. It then clefines the position of the renal vessels. The tail of the pancreas and the posterolateral wall of the lesser omental sac lie just above and inside them, and by inserting a probe $\mathrm{I}$ was able to enter the cavity of this sac, either through the mesocolon below the lower border of the pancreas or through the posterior peritoneum above this gland, at will, according to the obliquity upwards given to the probe. In no case was the suprarenal capsule or any other structure in the neighbourhood injured. When the lesser omental sac was distended with fluid fluctuation could be distinctly felt by the exploring finger working upwards above the renal vessels, and the fluid could be evacuated with ease by means of a drainage-tube made to enter the sac with the help of a director and a pair of dressing forceps. This procedure will be found to be quite as easy in cases of pancreatic cysts and probably of others in this neighbourhood. The cyst wall may be thick and thus a little difficult to penetrate, but that need not cause much trouble, while the long existent distension will have brought the cyst within more easy reach. It may even extend downwards below the line of the renal vessels, and thus be reached by the surgeon whether he goes above or below these structures. This method of reaching these cysts from behind was adopted by Mr. Cotterill with complete success in a case now under his care in the wards of the Royal Infirmary, Edinburgh. He entered the sac below the renal vessels. The patient is doing well. Others have adopted a posterior incision after an anterior one has failed. Thus Gould mentioned that in a case where the cyst was fixed and could not be brought to the surface, with a finger in the cyst he cut down behind below the twelfth rib and drained it posteriorly. The fistula rapidly closed up. A better proof could hardly be giren of the advantages of the posterior incision. He would doubtless have easily reached the cyst had he tried the posterior incision at first. I would strongly adrocate this method of procedure, not only because of its ease, but because of the advantages of a posterior over an anterior incision, and of the more perfect drainage and much more rapid convalescence and cure which it promises. Even if it were to fail to reach the cyst, it would in no way prejudice the success of an anterior exploration, and would, moreover, even in such a case, allow of the rapid establishment of posterior drainage.

Edinburgh.

\section{A CASE OF ULCERATIVE ENDOCARDITIS ASSOCIATED WITH COARCTATION OF THE AORTA.}

By THOS. B. FLINT, L.R.C.P. LOND., M.R.C.S. ExG., SENIOR HOOSE PHXSICIAY TO THE MIAXCHESTHR ROYAL INFIRMARY.

A MAN aged twenty-one came to the accident-room of the Manchester Royal Infirmary on May 20th, 1895, complaining of hæmoptysis, which had come on two days previously. The quantity of blood brought up was small. Phthisis was the first thing thought of. On examining his chest, however, no physical signs of that disease were manifest, but a double murmur heard best over the aortic area was discovered. Both systolic and diastolic murmurs were very loud and entirely replaced the heart sounds. On feeling the pulse it was found to be distinctly a "Corrigan's," and on rubbing the skin over the forehead capillary pulsation was well seen. He was admitted as an in-patient under the care of Dr. Steell. The next day a more detailed examination was made. The patient was a well-nourished man, but somewhat anæmic. On inspection it was noticed that there was marked pulsation in the supra-sternal notch and in the neck, especially the upper part. 'The apex beat was in the sixth left intercostal space and just outside the nipple line. On percussion the cardiac dulness extended three-quarters of an inch to the right of the mid-sternal line and four inches and a half to the left of it at a level of about one inch above the upper margin of the liver. Above, the dulness did not extend higher than the third rib. On auscultation the lond double murmur was heard as before in all four areas of the heart, replacing the sounds. When listening at the lower angle of the left scapula both murmurs could be plainly heard; but higher up, just below the scapular spine, the systolic murmur was alone heard and was remarkably loud. On looking more clowely along the surface of this area where the murmur was heard the loudest it was noticed to be pulsating, and numerous tortwous arteries, some of considerable size, could be seen beating in it, and on laying the hand over it a slight thrill could be felt. The pulsating area occupied practically the subspinous fossa. On the right side a similar condition existed, but it was not so well defined as on the left. The pupils were equal, and both radial arteries gave the same tracing-a typical aortic regurgitation one. As regards the other organs, the lungs were apparently normal. The sputum was examined several times for tubercle bacilli with negative results. The liver was slightly enlarged and projected about a finger's breadth below the costal margin. The spleen was also enlarged. The urine was normal. As regards his previous history, the patient stated that he had never suffered from rhen matism or chorea, that his work was not heavy that he had never noticed that he was short of breath, and had never had any swelling of the legs and feet. From the date of admission to the end of the second week of June the patient progressed very well. The pulse areraged about 100 , the respiration was about 18 per minute, and the temperature in the morning averaged about $98.2^{\circ} \mathrm{F}$. and in the evening about $100 \cdot 2^{\circ}$. The hæmoptysis almost disappeared. During the third week of June, although the patient did not complain, it was noticed that he was getting paler and his appetite began to fail. The pulse averaged 120, the respiration 20 , and the temperature in the morning $99^{\circ}$ and in the evening $100^{\circ}$. On June 24 th the patient complained of pain in his right side, and his temperature rose in the evening to $101 \cdot 2^{\circ}$. The next day he coughed up a considerable quantity of blood from the lungs. He perspired profusely and vomited during the day about three pints of undigested food. There was some dulness at the base of the right lung. A distinct bruit de galop was heard for the first time over the cardiac region. The superficial arteries could be seen pulsating much more plainly than before, and the urine contained some albumin. He gradually became worse, his pulse-rate increasing to 132 per minute, his raspiration to 54 , and his temperature to $101^{\circ}$, and he died on the 29th from heart failure.

Necropsy.-The brain and spinal cord were not examined. The pericardium was considerably increased in extent and there was a slight increase in the amount of pericardial fluid. The heart was greatly enlarged downwards and outwards, giving to the organ almost a bovine character. The weight was $1 \mathrm{lb}$. $5 \mathrm{oz}$. 'The right auricle was slightly dilated. The tricuspid orifice was slightly dilated; the segments were normal. The right ventricle was dilated and greatly hypertrophied. The pulmonary artery was apparently normal. The left auricle was dilated and hypertrophied. The mitral orifice was dilated and admitted three fingers; the segments were healthy. The left ventricle was dilated and greatly hypertrophied. The aortic segments were almost completely destroyed by masses of recent ulcerative endocarditic vegetations. Immediately above the valves a diverticulum, fully one inch in depth, projected as a polypoid growth into the cavity of the right auricle. About one inch beyond the origin of the left subclavian artery-i.e., at the junction of the transverse and descending aortas-the aorta became extremely narrowed and only admitted a small probe. The contraction extended over a very inconsiderable space and was sharply defined both at its commencement and at its termination. The ductus arteriosus was obliterated and terminated at the concave portion of the aorta about one-sixteenth of an inch above its contraction. The descending thoracic and abdominal aortas were of about normal size, but the iliac and femoral vessels were smaller than usual. Coming off from the descending aorta immediately below the constriction there was an artery as large as the brachial; this proved to be the first aortic intercostal. The posterior scapular arteries were much enlarged and tortuous and anastomosed with the upper intercostal branches close to the spine. These vessels formed the pulsating area described above. The internal mammary arteries weie also much enlarged. The liver was enlarged. The spleen wa 
enlarged cousiderably. The kidneys were healthy. The left lung was normal. The lower lobe of the right lung showed pneumonic consolidation and was in the stage of red hepatisation. There was a small amount of fluid in the right plenral cavity.

liemarks. - The condition of coarctation of the aorta, although rare, is by no means unique; I have, however, never seen a case recorded in which the patient was also the subject of ulcerative endocarditis. An interesting point in the case was the close resemblance it bore to pulmonary phthisis, the temperature, down in the morning and up in the evening, being very suggestive of this, but, of course, there was the presence of the valve lesion to account for it. The patient and his mother (a very intelligent woman) were certain that he had never had rheumatic fever or chorea, nor had he suffered from any other serious ailment previously. He had never undergone severe physical exertion, and his work had always been light. Then, again, the enlargement of the spleen is worthy of note, as is also the albuminuria which came on shortly before death. The temperature, too, was always more or less raised during the whole of his stay in hospital.

Manchester.

\section{A RARE FORM OF SKIN DISEASE FOLLOW- ING THE EXTERNAL APPLICATION OF IODINE LINTMENT. \\ BY D. ROBERTSON DOBIE, M.D. EDIN.}

IN The LaNCET of Sept. 29th, 1894, appeared two very interesting articles, the one upon an epidemic skin disease occurring in public institutions, and the other upon the treatment of small-pox, two very dissimilar subjects to allude to. I am induced from a study of those to think the following case will be of interest and importance on the one band to medical practitioners who devote their particular zattention to skin affections, and on the other hand to medical officers of health, who may at any moment be consulted as to the best means of checking the spread of disease amongst a oommunity. Dr. Henderson and I were at first in a dilemma noted. After his apprenticeship he enlisted and was sent to Egypt, and when abroad he became subject to epileptic fits and was discharged on that account. He came home and found employment in varions ways, feeling well and able for any amount of work. 'Three weeks before the present iliness he went to harvest work, and continued this employment four days, when he felt unwell. He worked when he felt able, and went to bed when he felt worse. He finally gave up and came home, but did not send for medical advice until the date of admission, when he was suffering from pneumonia and symptoms of advanced renal disease. On each succeeding day the temperature averaged from $98.4^{\circ}$ to $99^{\circ} \mathrm{F}$., with an evening rise not exceeding $100 \cdot 8^{\circ}$. The urine was highly coloured with bile, and thickly charged with albumin, fully two-thirds of a test-tube quantity. The amount ranged from seventy to eighty ounces. The usual treatment necessary for such cases was carried out with great, care and his condition every day carefully noted. The consolidation of the lung became most marked, and in every respect his condition might safely be said to be improving. It is unnecessary to go into every detail, but what I wish particularly to point out in the course of the treatment was the painting of the back with dilute iodine liniment, equal in strength to the Edinburgh tincture of iodine. This was applied morning and evening from Sept. 14th to the 18th. On the 19th the patient's face was completely covered with a papular, pustular, vesicular eruption; in some parts, more particularly in the region of the ear, a bullous eruption. These pustules all over the face were discrete and confluent, forming large encrusted sores, with swelling of the eyelids, lips, nose, and ears. A copious discharge from the nostrils accompanied this. The face was increased enormously in size. At the same time a perfectly different, purely papular eruption made its appearance upon the back of the hands, wrists, and forearms. The patient experienced severe smarting and heat in the face ; in other respects there was no change in his condition. My colleague and myself were at first not a little alarmed at this sudden development, more particularly when we discovered, on making inquiries, that he had been sleeping during the time he was at the farm in a bed adjoining two strangers, labourers from the county of Durham. The period of incubation of small-pox would not tally with his account of the dates, and on consulting Dr. Radcliffe Crocker's able work on "Skin Diseases" and Plate 33 of the Sydenham Society "Atlas of Skin Diseases" I discovered

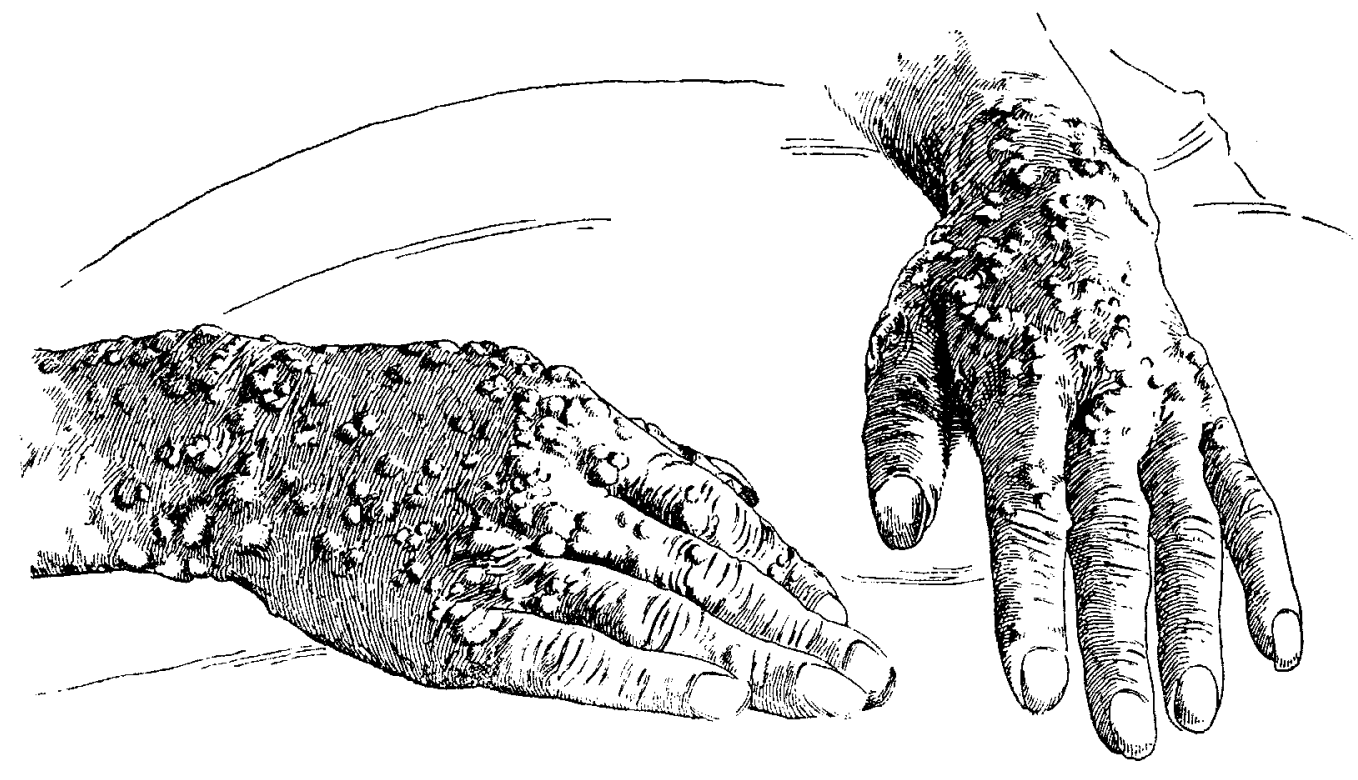

as to what was the nature of a most suspicious eruption which made its appearance in a case under treatment in the Coldstream Cottage Hospital. The following are the history and notes of the case, and I am of opinion that, although not by any means unique, it is of sufficient rarity to make it worth recording.

On Sept. 13th, 1894, I was summoned to visit a man aged swenty-four years who had been ill for about four days with headache, lassitude, and pain in the back. I found the patient with a high temperature and double pneumonia. I ordered his immediate removal to the Coldstream Cottage Hiospital, where a more thorough and complete examination as to bis condition was made. His previous history may be shortly that we had a case of iodide eruption. The eruption on the face in the course of four days gradually died away, leaving healthy epiclermis and no scar", the scabs peeling off rapidly. The papules on the hands continued very prominent. On careful examination it was easily seen that the papilloma was a distinct epithelial growth upwards. On puncture a clear viscid fluid escaped; no pus was found in any of them. There was a well-marked red ring round the base of each, ancl not one liad the slightest appearance of subsiding. On Sept. 27th the patient complained to the nurse in attendance of headache and chilliness all over his body. His temperature was $99.4^{\circ}$ at 8 o'clock in the morning. At 12 o'clock he was seized with sickness, nausea, 